CHRONIC OBSTRUCTIVE PULMONARY DISEASE

\title{
Sputum eosinophilia and the short term response to inhaled mometasone in chronic obstructive pulmonary disease
}

\author{
C E Brightling, S McKenna, B Hargadon, S Birring, R Green, R Siva, M Berry, D Parker, \\ W Monteiro, I D Pavord, P Bradding
}

Thorax 2005;60:193-198. doi: 10.1136/thx.2004.032516

See end of article for authors' affiliations

\section{Correspondence to:}

$\operatorname{Dr} C$ E Brightling, Institute for Lung Health, Clinical Sciences Wing, University Hospitals of Leicester, Groby Road, Leicester LE3 9QP, UK; ceb17@le.ac.uk

Received 4 August 2004 Accepted

18 December 2004

\begin{abstract}
Background: An association between the sputum eosinophil count and the response to a 2 week course of prednisolone has previously been reported in patients with chronic obstructive pulmonary disease (COPD). Whether the response to inhaled corticosteroids is related to the presence of eosinophilic inflammation is unclear.

Methods: A randomised, double blind, crossover trial of placebo and mometasone furoate (800 $\mu \mathrm{g} /$ day), each given for 6 weeks with a 4 week washout period, was performed in subjects with COPD treated with bronchodilator therapy only. Spirometric tests, symptom scores, chronic respiratory disease questionnaire $(C R Q)$, and induced sputum were performed before and after each treatment phase.

Results: Ninety five patients were recruited of which 60 were randomised. Overall there were no treatment associated changes in forced expiratory volume in 1 second $\left(\mathrm{FEV}_{1}\right)$, total $C R Q$, or sputum characteristics. After stratification into tertiles by baseline eosinophil count, the net improvement in post-bronchodilator $\mathrm{FEV}_{1}$ increased with mometasone compared with placebo progressively from the least to the most eosinophilic tertile. The mean change in post-bronchodilator $\mathrm{FEV}_{1}$ with mometasone compared with placebo in the highest tertile was 0.11 I (95\% Cl 0.03 to 0.19 ). This improvement was not associated with a fall in the sputum eosinophil count.

Conclusions: An increased sputum eosinophil count is related to an improvement in post-bronchodilator $\mathrm{FEV}_{1}$ following treatment with inhaled mometasone in COPD, but the improvement is not associated with a reduction in the sputum eosinophil count.
\end{abstract}

$\mathrm{T}$ e use of inhaled corticosteroids in stable chronic obstructive pulmonary disease (COPD) remains controversial. ${ }^{1}$ The Global initiative for chronic obstructive lung disease (GOLD) and National Institute for Clinical Excellence (NICE) guidelines suggest that they should be reserved for patients with severe COPD and frequent exacerbations. ${ }^{23}$

Corticosteroids are very effective in modifying eosinophilic airway inflammation in asthma, ${ }^{45}$ but there is less evidence that they reduce neutrophilic inflammation which predominates in COPD. ${ }^{6}$ One possibility is that corticosteroids are most effective in COPD patients who have eosinophilic airway inflammation. $\mathrm{We}^{7}$ and others ${ }^{8}$ have shown that subjects with a sputum eosinophilia ( $>3 \%$ non-squamous cells) had a greater improvement in forced expiratory volume in 1 second $\left(\mathrm{FEV}_{1}\right)$ and health status with a short course of oral prednisolone than with placebo. Whether the response to inhaled corticosteroids is similarly related to the presence of eosinophilic inflammation is unclear. Identification of a biomarker that can distinguish which patients with COPD may benefit the most from inhaled corticosteroid therapy would be a useful guide in the management of this disease.

We have performed a double blind, placebo controlled, crossover study to investigate the relationship between the sputum eosinophil count and the response to 6 weeks of treatment with the inhaled corticosteroid mometasone furoate.

\section{METHODS}

Subjects with symptoms of chronic airflow obstruction and a post-bronchodilator $\mathrm{FEV}_{1}$ of $<70 \%$ predicted and ratio of $\mathrm{FEV}_{1}$ to forced vital capacity (FVC) of $<70 \%$ were recruited from respiratory clinics. All had no significant improvement in $\mathrm{FEV}_{1}$ after $200 \mu \mathrm{g}$ inhaled salbutamol $\left(<15 \%\right.$ or, if $\mathrm{FEV}_{1}$
$<1.2 \mathrm{l},<200 \mathrm{ml}$ improvement). Subjects were excluded if they had a clinical diagnosis of asthma, a history of childhood respiratory problems, variability in symptoms not associated with infections, a history of acute wheeze, breathlessness or deterioration associated with allergens, or an exacerbation within 6 weeks of trial entry. Subjects taking regular oral corticosteroids were excluded. Inhaled or oral corticosteroids were discontinued for at least 1 month prior to randomisation. Subjects were withdrawn from the study if they had a moderate exacerbation requiring inhaled corticosteroids or antibiotics, a severe exacerbation needing oral corticosteroids, or a severe intercurrent illness.

The study was approved by the local research ethics committee and all subjects gave written informed consent.

\section{Study design}

The study was of a randomised, double blind, placebo controlled, crossover design. Subjects were randomised to receive mometasone furoate $800 \mu \mathrm{g}$ once daily and placebo administered via a Twisthaler in random order for 6 weeks each (Schering-Plough, UK). The treatment periods were preceded by a 4 week run-in period and separated by a 4 week washout period. Subjects attended on four occasions before and 12 hours after the last dose of study medication. They were seen at the same time of day at least 6 hours after their last dose of bronchodilator and 24 hours after the last dose of long acting $\beta_{2}$ agonists. At the initial visit details of the subject's smoking, treatment, atopic and childhood

Abbreviations: COPD, chronic obstructive pulmonary disease; $C R Q$, Chronic Respiratory Disease Questionnaire; ECP, eosinophilic cationic protein; $F E V$, forced expiratory volume in 1 second; FVC, forced vital capacity; IL-8, interleukin 8; SOB, shortness of breath; TCC, total cell count; VAS, visual analogue score 
respiratory history were obtained and blood was taken to assess peripheral blood eosinophil count, total immunoglobulin (Ig)E and RAST tests to Dermatophagoides pteronyssinus, cat fur, and grass pollen. At each visit the following were performed: (1) symptom scores using a $100 \mathrm{~mm}$ visual analogue scale from no symptom to the worst symptom ever for dyspnoea, cough, sputum production and wheeze; (2) spirometry before and after inhaled salbutamol $200 \mu \mathrm{g}$; (3) the Chronic Respiratory Disease Questionnaire (CRQ); ${ }^{9}$ and (4) sputum induction. Sputum was induced and processed as previously described..$^{10}$

\section{Mediator measurements}

Sputum interleukin (IL)-8 was measured using an ELISA (Pharmingen, UK), eosinophilic cationic protein (ECP) was measured using a fluoroimmunoassay (Pharmacia, Milton Keynes, UK), and histamine was measured using a radioenzymic assay. We have validated these assays for the analysis of sputum supernatants. ${ }^{811}$

\section{Analysis of data}

The primary outcomes were change in the post-bronchodilator $\mathrm{FEV}_{1}$ and total CRQ after mometasone compared with placebo. The secondary outcome measures were the individual CRQ domains, symptom scores, and sputum characteristics. Period and order effects were assessed by comparing the primary outcomes before each treatment phase (visit 1 versus visit 3) and before each treatment (mometasone versus placebo) by paired $t$ tests. To assess the association between sputum eosinophil count and primary outcomes, subjects were divided into tertiles by their baseline sputum eosinophil count. The study was powered to have a $>80 \%$ chance at the $5 \%$ level of detecting a $100 \mathrm{ml}$ difference in the change in $\mathrm{FEV}_{1}$ within tertiles, assuming a within subject standard deviation of $100 \mathrm{ml} .{ }^{12}$ Subjects who were randomised but did not complete the study were included on an intention to treat basis. Subjects who withdrew in the washout phase were assigned a net change of zero for the second treatment phase, and subjects who withdrew during a treatment phase were assigned a change two standard deviations below the group mean change for that treatment phase for each of the outcome variables. All data were analysed using Minitab version 13. Improvement in the outcome variables after mometasone compared with placebo was assessed using paired $t$ tests and differences in the subject characteristics between tertiles were compared by analysis of variance or the Kruskal-Wallis test for parametric and non-parametric data, respectively.

The following post hoc analyses were performed: (1) the association between total IgE, peripheral blood eosinophil count and sputum ECP concentration with the primary outcomes by similarly stratifying the subjects into tertiles for each of these three parameters; (2) the association between smoking status and previous corticosteroid usage with the primary outcomes; and (3) the study was re-analysed to include only those subjects who completed the study. All reported $\mathrm{p}$ values are two tailed.

\section{RESULTS}

Ninety five subjects were recruited of which 60 were randomised. Twelve of the 56 subjects taking inhaled corticosteroids at the time of recruitment developed moderate exacerbations in the run-in period following corticosteroid withdrawal and 15 developed bronchodilator reversibility at randomisation. Three subjects withdrew from the study during the washout period following mometasone treatment and five after placebo. Three withdrew during the second treatment phase, two while receiving mometasone and one while receiving placebo (fig 1).

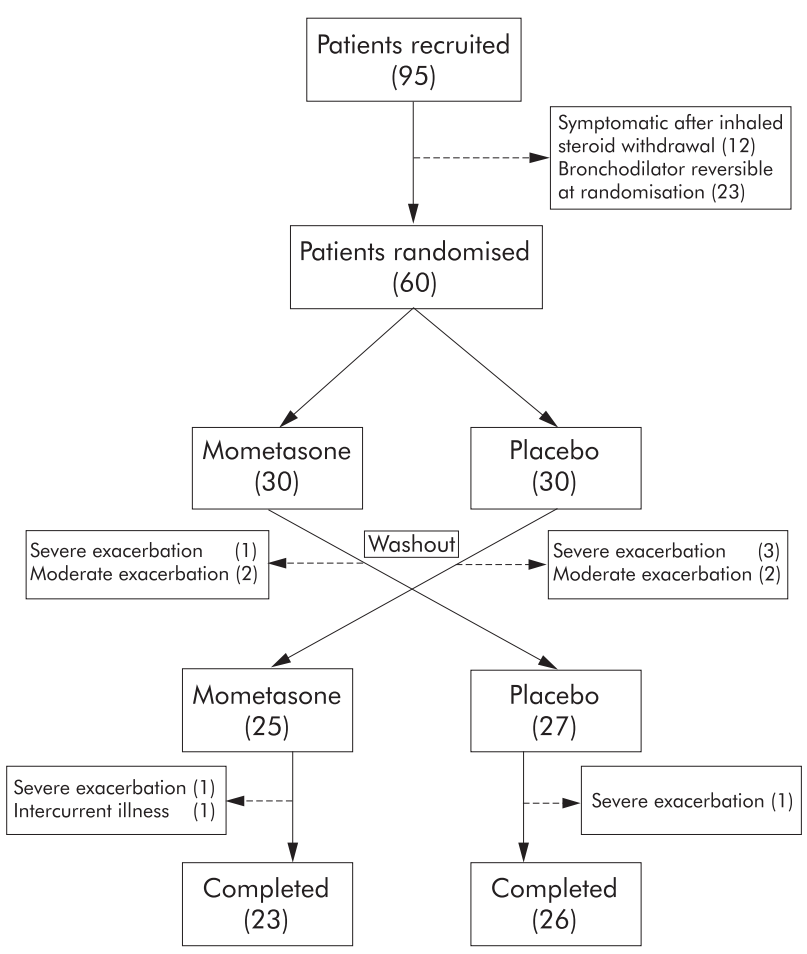

Figure 1 Study pathway from recruitment to completion.

Treatment period or order did not influence pre-treatment values or the changes in the sputum eosinophil count or primary outcome variables. The mean difference $(95 \% \mathrm{CI})$ between the post-bronchodilator $\mathrm{FEV}_{1}$ and total CRQ before each treatment phase (visit $1 v$ visit 3$)$ were: $0.01(-0.04$ to $0.05 ; \mathrm{p}=0.8)$ and $0.01(-0.16$ to $0.18 ; \mathrm{p}=0.9)$, and before each treatment (mometasone $v$ placebo) were: $0.04(-0.01$ to $0.09 ; \mathrm{p}=0.12)$ and $0.12(-0.18$ to $0.31 ; \mathrm{p}=0.36)$, respectively. Similarly, the sputum eosinophil count was not significantly different before each treatment phase $(\mathrm{p}=0.24)$ or treatment $(\mathrm{p}=0.8)$.

The group geometric mean sputum eosinophil count decreased after mometasone from $2.20 \%$ to $1.58 \%$, but this change was not significantly different from the change after placebo $(2.32 \%$ to $1.96 \%$; 1.17 -fold decrease after mometasone compared with placebo (95\% CI 0.7 to 1.4 ), $\mathrm{p}=0.38$, table 1). There were no other significant changes in sputum cell counts or sputum mediator concentrations (table 1).

The mean paired difference between mometasone and placebo treatment for the change in primary outcomes for the whole group were: post-bronchodilator $\mathrm{FEV}_{1} 0.04 \mathrm{l}$ (95\% CI -0.03 to $0.11 ; \mathrm{p}=0.24)$ and CRQ total $-0.025(95 \% \mathrm{CI}-0.23$ to $0.18 ; \mathrm{p}=0.8$ ).

Stratified in tertiles by the baseline eosinophil differential cell count, the subjects were well matched for age, sex, smoking history, atopy and there was no significant difference in baseline spirometry or total CRQ (table 2). The peripheral blood eosinophil count and total IgE concentration was higher in the most eosinophilic tertile $(p<0.05)$. There was a progressive increase in the mean difference between mometasone and placebo from the least to the most eosinophilic tertiles for change in post-bronchodilator $\mathrm{FEV}_{1}$ and total CRQ (fig 2). The mean change in post-bronchodilator $\mathrm{FEV}_{1}$ with mometasone compared with placebo in the highest tertile was $0.11 \mathrm{l}$ (95\% CI 0.03 to $0.19 ; \mathrm{p}=0.02)$. Similarly, an improvement in pre-bronchodilator $\mathrm{FEV}_{1}$ was only observed in those subjects in the highest tertile (0.096 l (95\% CI 0.00 to 0.19 ); $\mathrm{p}=0.05$ ). There was no significant 
Table 1 Primary outcomes: post-bronchodilator $\mathrm{FEV}_{1}$ and total $\mathrm{CRQ}$ and sputum characteristics before and after mometasone and placebo for the whole group $(n=60)$

\begin{tabular}{|c|c|c|c|c|c|c|c|}
\hline & Pre-ICS & Post-ICS & $\begin{array}{l}\text { p value } \\
\text { (pre } v \text { post } \\
\text { ICS) }\end{array}$ & Pre-placebo & Post-placebo & $\begin{array}{l}\text { p value } \\
\text { (pre } v \text { post } \\
\text { placebo) }\end{array}$ & $\begin{array}{l}\text { p value } \\
\text { (net } \\
\text { improvement) }\end{array}$ \\
\hline $\mathrm{FEV}_{1}$ (l) & $1.25(0.07)$ & $1.25(0.07)$ & 0.4 & $1.17(0.07)$ & $1.15(0.07)$ & 0.6 & 0.35 \\
\hline $\mathrm{FEV}_{1}$ (I) post-bronchodilator & $1.34(0.08)$ & $1.37(0.08)$ & 0.31 & $1.25(0.07)$ & $1.24(0.08)$ & 0.77 & 0.36 \\
\hline$C R Q$ total & $4.15(0.15)$ & $4.4(0.16)$ & 0.015 & $4.15(0.17)$ & $4.54(0.17)$ & 0.018 & 0.8 \\
\hline Total cell count $10^{6} / \mathrm{g}$ sputum & $2.8(0.4)$ & $3.7(1.1)$ & 0.5 & $3.7(0.6)$ & $4.9(1.4)$ & 0.27 & 0.66 \\
\hline Eosinophils (\%)† & $2.20(0.07)$ & $1.58(0.08)$ & 0.014 & $2.32(0.09)$ & $1.96(0.09)$ & 0.25 & 0.38 \\
\hline Neutrophils $(\%) \ddagger$ & $77.9(61-89)$ & $80.3(62-90)$ & 0.21 & $77.9(63-89)$ & $75.1(67-87)$ & 0.63 & 0.22 \\
\hline Macrophages $(\%) \ddagger$ & $14.5(7-31)$ & $11.8(8-30)$ & 0.12 & $14.2(5-25)$ & $14.9(7-20)$ & 0.53 & 0.42 \\
\hline Bronchial epithelial cells (\%)‡ & $1.3(0.5-2.6)$ & $1.6(0.4-3.7)$ & 0.15 & $1.4(0.2-1.9)$ & $1.1(0.4-3.1)$ & 0.08 & 0.56 \\
\hline Lymphocytes (\%)‡ & $0.4(0.18-1.0)$ & $0.4(0-0.8)$ & 0.5 & $0.4(0.70 .1-0.8)$ & $0.5(0.2-0.9)$ & 0.69 & 0.85 \\
\hline Histamine $(\mathrm{ng} / \mathrm{g}) \dagger$ & $49(0.09)$ & $50(0.09)$ & 0.6 & $59(0.08)$ & $51(0.09)$ & 0.79 & 0.35 \\
\hline IL-8 (ng/g)† & $109(0.06)$ & $95(0.05)$ & 0.21 & $118(0.06)$ & $123(0.06)$ & 0.13 & 0.13 \\
\hline ECP $(n g / g) \dagger$ & $1115(0.07)$ & $1021(0.08)$ & 0.4 & $982(0.09)$ & $1060(0.09)$ & 0.12 & 0.09 \\
\hline
\end{tabular}

$\mathrm{FEV}_{1}$, forced expiratory volume in 1 second; CRQ, Chronic Respiratory Disease Questionnaire; ICS, inhaled corticosteroid; IL-8, interleukin 8; ECP, eosinophilic cationic protein.

Values are mean (SE) except tgeometric mean (log SE), łmedian (IQR).

improvement in total CRQ or in the other secondary outcome measures in any of the tertiles (fig 2, table 3). There was no significant reduction in the sputum eosinophil count in the two tertiles with the highest baseline eosinophil count and in the lowest tertile the sputum eosinophilic count increased after mometasone compared with placebo, although this represented a very small change in the absolute sputum eosinophil count in this group (table 3).

The following post hoc analyses were performed. (1) We re-analysed the study stratifying the subjects into tertiles defined by their baseline total IgE, peripheral blood eosinophil count, and sputum ECP. The improvement in post-bronchodilator $\mathrm{FEV}_{1}$ after mometasone compared with placebo was highest in those subjects in the highest tertile for all of these measures, but this improvement did not reach statistical significance (table 4). There was no significant

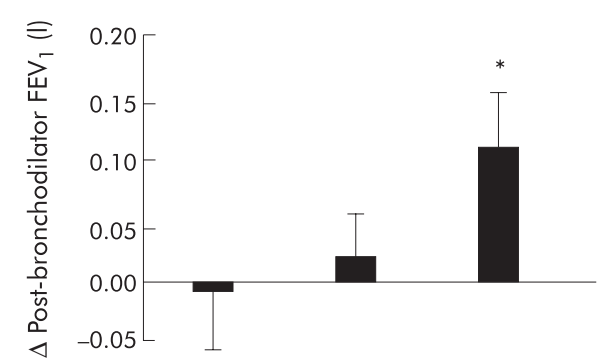

Least to most eosinophilic tertile

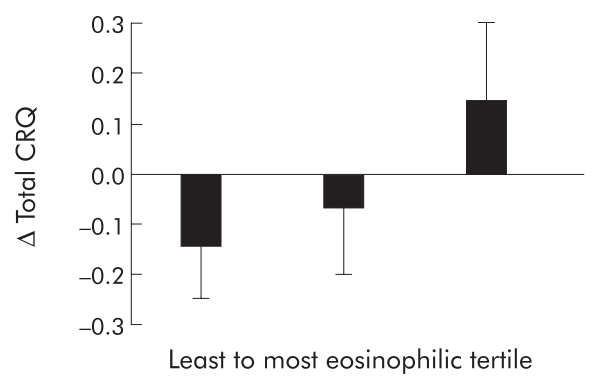

Figure 2 Mean (SE) absolute increase in post-bronchodilator forced expiratory volume in 1 second $\left(\mathrm{FEV}_{1}\right)$ and total Chronic Respiratory Disease Questionnaire (CRQ) score after mometasone compared with placebo for each tertile. ${ }^{*} \mathrm{p}<0.05$ (paired $t$ test). There was improvement after mometasone compared with placebo in each group. change in total CRQ in any of the tertiles (data not shown). (2) The mean improvement in post-bronchodilator $\mathrm{FEV}_{1}$ was not significantly increased in those subjects who were ex- or never current smokers (0.06 l (95\% CI -0.21 to 0.14$)$; $\mathrm{p}=0.15)$ or current smokers $(-0.03 \mathrm{l}(95 \% \mathrm{CI}-0.16$ to $0.11) ; \mathrm{p}=0.7)$, and there was no significant difference between ex- or never smokers and current smokers (mean difference $0.08 \mathrm{l}(95 \% \mathrm{CI}-0.08$ to 0.24$) ; \mathrm{p}=0.3)$. There was no relationship between smoking status and total CRQ or previous corticosteroid usage and any of the primary outcomes (data not shown). (3) We re-analysed the data including only those 49 subjects who completed the study. These subjects were again stratified into tertiles based on their baseline sputum eosinophil count. The findings were very similar to the intention-to-treat analysis with a mean improvement in post-bronchodilator $\mathrm{FEV}_{1}$ after mometasone compared with placebo of 0.111 (95\% CI 0.002 to 0.21 ; $\mathrm{p}=0.046)$.

\section{DISCUSSION}

We have shown that, in subjects with stable moderate and severe COPD, there is a small but significant improvement in post-bronchodilator $\mathrm{FEV}_{1}$ in subjects with higher baseline sputum eosinophil count. This improvement was not associated with a fall in the sputum eosinophil count or a change in any other sputum marker of eosinophilic or neutrophilic inflammation.

Our findings suggest that systemic and inhaled corticosteroids have differential effects on airway inflammation in COPD. In this study inhaled corticosteroid treatment did not modify eosinophilic airway inflammation in the whole group compared with placebo whereas, in our previous report in a similar group of patients with COPD, prednisolone caused a marked reduction in the sputum eosinophil count. ${ }^{8}$ This suggests that the airway inflammation in COPD is relatively insensitive to inhaled corticosteroid therapy.

Indeed, there was a significant (albeit small) increase in the sputum eosinophil count in the tertile with the least eosinophilic inflammation at baseline after mometasone compared with placebo. The differences between the effects of oral versus inhaled corticosteroids may reflect differences in dose or perhaps the site of action. Systemic corticosteroids are likely to exert more of an effect on small airway inflammation, which is less accessible to inhaled therapy, and systemic corticosteroids also suppress eosinophil production by the bone marrow.

Our study supports a role for the sputum eosinophil count in identifying subjects who may benefit from inhaled 
Table 2 Baseline characteristics of subjects stratified in tertiles defined by the baseline eosinophil differential cell count

\begin{tabular}{|c|c|c|c|}
\hline & \multicolumn{3}{|l|}{ Eosinophil count } \\
\hline & $<1(n=20)$ & $1-3.9(n=20)$ & $>3.9(n=20)$ \\
\hline Male & 10 & 15 & 15 \\
\hline Age (years)† & $66(2)$ & $68(2)$ & $68(2)$ \\
\hline Current smoker & 5 & 9 & 5 \\
\hline Ex-smokers & 14 & 11 & 14 \\
\hline Pack years $†$ & $40(5)$ & $41(6)$ & $39(5)$ \\
\hline $\begin{array}{l}\text { Treated with long acting } \\
\beta_{2} \text { agonists (n) }\end{array}$ & 4 & $\beta_{2}$ agonists (n) & 4 \\
\hline Atopic (subjects with +ve RAST) & 7 & 6 & 9 \\
\hline $\lg E(k U / l) \dagger$ & $77(21)$ & $63(13)$ & $197(53)^{*}$ \\
\hline Blood eosinophil count $\left(\times 10^{9} / \mathrm{I}\right) \ddagger$ & $0.15(0.02)$ & $0.25(0.04)$ & $0.37(0.06)^{*}$ \\
\hline Total CRQ† & $4.0(0.3)$ & $3.9(0.2)$ & $4.5(0.3)$ \\
\hline $\mathrm{FEV}_{1}(\mathrm{I}) \dagger$ & $1.35(0.13)$ & $1.29(0.1)$ & $1.03(0.09)$ \\
\hline $\mathrm{FEV}_{1} \mathrm{BD}(\mathrm{l}) \dagger$ & $1.47(0.14)$ & $1.42(0.11)$ & $1.09(0.1)$ \\
\hline $\mathrm{FEV}_{1}(\%$ predicted $) \dagger$ & $47(3)$ & $47(3)$ & $38(3)$ \\
\hline FVC (I)† & $2.5(0.2)$ & $2.3(0.2)$ & $2.2(0.2)$ \\
\hline \multicolumn{4}{|l|}{ Sputum characteristics } \\
\hline Eosinophils (\%) & $0.4(0.1)$ & $2(0.04)$ & $7.5(0.05)$ \\
\hline Neutrophils (\%) & $67(41-89)$ & $81(68-84)$ & $80(65-89)$ \\
\hline Macrophages (\%) & $29(10-53)$ & $14(9-27)$ & $10(4-24)$ \\
\hline Lymphocytes (\%) & $0.5(0.16-0.9)$ & $0.8(0.05-1.25)$ & $0.2(0-0.7)$ \\
\hline Epithelial cells (\%) & $0.8(10.2-2.2)$ & $0.9(0.2,2.4)$ & $0.9(0.2-2.5)$ \\
\hline TCC $\left(\times 10^{6}\right.$ cells $/ g$ sputum $) \dagger$ & $4.8(1.4)$ & $2.9(0.5)$ & $3.7(1.0)$ \\
\hline Histamine (ng/g) $\ddagger$ & $45(0.17)$ & $84(0.16)$ & $48(0.1)$ \\
\hline IL-8 (ng/g) $\ddagger$ & $135(0.9)$ & $100(0.08)$ & $142(0.1)$ \\
\hline ECP $(n g / g) \ddagger$ & $687(0.09)$ & $998(0.1)$ & $1769(0.2)$ \\
\hline \multicolumn{4}{|l|}{$C R Q$ domain scores } \\
\hline Dyspnoea† & $3.3(0.3)$ & $3.1(0.3)$ & $3.7(0.3)$ \\
\hline Fatiguet & $3.6(0.3)$ & $3.5(0.2)$ & $4.0(0.3)$ \\
\hline Emotiont & $4.4(0.3)$ & $4.5(0.2)$ & $4.9(0.3)$ \\
\hline Mastery† & $4.5(0.3)$ & $4.5(0.3)$ & $5.3(0.3)$ \\
\hline \multicolumn{4}{|l|}{ Symptom scores (VAS) } \\
\hline Cough $(\mathrm{mm}) \dagger$ & $35(7)$ & $34(6)$ & $43(7)$ \\
\hline Sputum $(\mathrm{mm}) \dagger$ & $25(6)$ & $38(6)$ & $26(5)$ \\
\hline $\mathrm{SOB}(\mathrm{mm}) \dagger$ & $51(7)$ & $48(5)$ & 45 (7) \\
\hline Wheeze $(\mathrm{mm}) \dagger$ & $27(6)$ & $25(5)$ & $32(6)$ \\
\hline \multicolumn{4}{|c|}{$\begin{array}{l}\text { FEV } 1 \text {, forced expiratory volume in } 1 \text { second; FVC, forced vital capacity; BD, bronchodilator; CRQ, Chronic } \\
\text { Respiratory Disease Questionnaire; TCC, total cell count; IL-8, interleukin 8; ECP, eosinophilic cationic protein; } \\
\text { SOB, shortness of breath; VAS, visual analogue score. } \\
\text { †Mean (SE), tgeometric mean (log SE), Tmedian (IQR). } \\
{ }^{*} \mathrm{p}<0.05 \text { comparison across groups (ANOVA or Kruskal-Wallis test). }\end{array}$} \\
\hline
\end{tabular}

Table 3 Mean $(95 \% \mathrm{Cl})$ change in secondary outcomes: CRQ domains, symptoms and sputum characteristics after mometasone compared with placebo for each tertile

\begin{tabular}{|c|c|c|c|}
\hline & \multicolumn{3}{|l|}{ Eosinophil count } \\
\hline & $<1(n=20)$ & $1-3.9(n=20)$ & $>3.9(n=20)$ \\
\hline \multicolumn{4}{|l|}{ CRQ domains $\ddagger$} \\
\hline SOB & $-0.31(-0.9$ to 0.3$)$ & $-0.2(-0.9$ to 0.5$)$ & $0.35(-0.3$ to 1.0$)$ \\
\hline Fatigue & $-0.16(-0.67$ to 0.35$)$ & $-0.19(-1.05$ to 0.67$)$ & $0.15(-0.41$ to 0.71$)$ \\
\hline Emotion & $-0.23(-0.63$ to 0.17$)$ & $-0.44(-0.89$ to 0.003$)$ & $-0.09(-0.69$ to 0.51$)$ \\
\hline Mastery & $-0.32(-0.79$ to 0.13$)$ & $-0.08(-0.78$ to 0.60$)$ & $0.31(-0.40$ to 1.02$)$ \\
\hline \multicolumn{4}{|l|}{ Symptom scores (VAS) } \\
\hline Cough & $2(-8$ to 13$)$ & $10(-1$ to 21$)$ & $3(-3$ to 8$)$ \\
\hline Sputum & $-15(-30$ to 0$)$ & $3(-8$ to 14$)$ & $-5(-17$ to 7$)$ \\
\hline SOB & $-12(-30$ to 7$)$ & $5(-4$ to 13$)$ & $-3(-16$ to 10$)$ \\
\hline Wheeze & $-8(-17$ to 2$)$ & $3(-4$ to 10$)$ & $-7(-17$ to 4$)$ \\
\hline \multicolumn{4}{|l|}{ Sputum indices } \\
\hline TCC $\neq$ & $-0.3(-3.2$ to 2.7$)$ & $1.9(-5.7$ to 9.4$)$ & $0.1(-1.7$ to 2.0$)$ \\
\hline Eosinophils $\uparrow$ & $0.44(0.27 \text { to } 0.73)^{*}$ & $0.9(0.42$ to 1.96$)$ & 1.37 (0.74 to 2.54$)$ \\
\hline Neutrophils $\ddagger$ & $-7.9(-23$ to 8$)$ & $2.3(-7$ to 12$)$ & $-7.2(-18$ to 4$)$ \\
\hline Histamine $(\mathrm{ng} / \mathrm{g}) \dagger$ & $1.1(0.5$ to 1.4$)$ & 0.8 (0.5 to 1.2 ) & $0.9(0.7$ to 1.1$)$ \\
\hline IL-8 (ng/g)† & $1.2(0.9$ to 1.6$)$ & $1(0.7$ to 1.5$)$ & $1.3(0.9$ to 1.8$)$ \\
\hline ECP $(\mathrm{ng} / \mathrm{g}) \dagger$ & 1.2 (0.96 to 1.5$)$ & $0.9(0.58$ to 1.48$)$ & 1.15 (0.9 to 1.45$)$ \\
\hline
\end{tabular}

$C R Q$, Chronic Respiratory Disease Questionnaire; SOB, shortness of breath; VAS, visual analogue score; TCC, total cell count; IL-8, interleukin 8; ECP, eosinophilic cationic protein.

${ }^{*} \mathrm{p}<0.05$.

†Fold decrease; fabsolute increase, ๆabsolute decrease (mm). 
Table 4 Mean $\left(95 \% \mathrm{Cl}\right.$ ) change in post-bronchodilator $\mathrm{FEV}_{1}$ (I) after mometasone compared with placebo for each tertile for patients stratified by baseline peripheral blood eosinophil count, total $\lg \mathrm{E}$, and sputum ECP concentration

\begin{tabular}{llll}
\hline & Lowest tertile & Middle tertile & Highest tertile \\
\hline Blood eosinophil count & $-0.0(-0.08$ to 0.08$)$ & $0.05(-0.08$ to 0.18$)$ & $0.05(-0.1$ to 0.19$)$ \\
Total lgE & $0.03(-0.11$ to 0.16$)$ & $-0.04(-0.15$ to 0.07$)$ & $0.10(-0.01$ to 0.22$)$ \\
Sputum ECP & $0.02(-0.14$ to 0.18$)$ & $-0.01(-0.09$ to 0.08$)$ & $0.08(-0.03$ to 0.19$)$ \\
\hline
\end{tabular}

corticosteroids. However, the inability of inhaled corticosteroids to modulate eosinophilic inflammation questions the importance of the eosinophil in the pathogenesis of stable COPD. The lack of effect on eosinophilic inflammation in COPD by inhaled corticosteroids is a consistent finding. ${ }^{53-16}$ Two studies have shown a small reduction in the sputum neutrophil count $t^{13}{ }^{17}$ and one a reduction in submucoasl mast cell numbers. ${ }^{14}$ Louis et al reported increased mast cell activation in a subset of patients with COPD who have a sputum eosinophilia, ${ }^{18}$ but we found no association between histamine concentration and baseline sputum eosinophilia. Thus, the role of the mast cell in the inflammatory response in COPD remains unclear.

There is a great deal of interest in the role of long term inhaled corticosteroid treatment in COPD. Regular treatment with inhaled corticosteroids in stable COPD does not alter the long term decline in lung function ${ }^{19-22}$ and there is conflicting evidence whether inhaled corticosteroids alter mortality. ${ }^{23}{ }^{24}$ However, they do reduce the number of exacerbations and improve health status in subjects with severe COPD. ${ }^{21}{ }^{25-27}$ One important question is whether these relatively minor long term benefits are confined to a definable subgroup of patients. Intriguingly, the exacerbation frequency in patients treated with inhaled fluticasone was less in those who responded to short term treatment with prednisolone than in non-responders. ${ }^{28}{ }^{29}$ It is therefore of interest that, while mometasone did not modify sputum eosinophils, there was nevertheless a small but significant increase in postbronchodilator $\mathrm{FEV}_{1}$ in the most eosinophilic tertile. Since sputum eosinophilia was also associated with an improvement in lung function after a short course of prednisolone, it is possible that the identification of eosinophilic airway inflammation might still allow corticosteroid therapy to be targeted to a population who would particularly benefit in the long term. This approach has been applied to asthma where, in a management strategy aimed at normalising the sputum eosinophil count, there was a striking reduction in severe exacerbations. ${ }^{30}$ Whether a similar approach would be equally successful in COPD needs to be addressed.

One criticism of sputum induction in the assessment of airway inflammation is that it requires skilled technical support. It is therefore attractive to consider alternative noninvasive measures. Importantly, we found that the total serum IgE and peripheral blood eosinophil count were increased in those subjects in the tertile with the highest baseline sputum eosinophil count. We therefore re-analysed our data to assess whether these measures and sputum ECP concentration could also identify subjects who respond to inhaled corticosteroids. Although improvement in lung function was best in those subjects in the highest tertile for all of these measures, this improvement was not significant and was not as good as those subjects with a high baseline sputum eosinopil count. This study therefore further supports the role of the sputum eosinophil count in the management of patients with COPD, but we have not identified an alternative marker in the peripheral blood.

One shortcoming of our study is that we may have recruited a group of patients with COPD who would be predicted to have a poor response to corticosteroids and therefore we may have underestimated the beneficial effect of mometasone. In particular, our subjects had no history suggestive of asthma and no significant bronchodilator response to short acting bronchodilators on two occasions. Furthermore, we excluded subjects who had an exacerbation during the run-in period after inhaled corticosteroid withdrawal. This group is likely to include those patients with COPD who have more corticosteroid responsive disease. Interestingly, the response to inhaled corticosteroids was not significantly associated with smoking status.

In conclusion, we found that a high sputum eosinophil count did identify a subgroup of patients with COPD who respond to inhaled corticosteroids in terms of lung function. This benefit was small and was not associated with a modification in eosinophilic airway inflammation, in striking contrast to our earlier findings with oral prednisolone, suggesting a degree of resistance to inhaled corticosteroid in COPD. Further studies are required to investigate the role of induced sputum as a predictor of the long term response to inhaled corticosteroids and, in particular, its value in guiding the use of corticosteroid therapy to reduce exacerbations in COPD.

\section{ACKNOWLEDGEMENTS}

The authors thank the Pharmacy Department, Glenfield Hospital for subject randomisation and allocation of medicines and the Department of Immunology, University Hospitals of Leicester for the measurement of eosinophilic cationic protein.

\section{Authors' affiliations}

C E Brightling, S McKenna, B Hargadon, S Birring, R Green, R Siva, M Berry, D Parker, W Monteiro, I D Pavord, P Bradding, Institute for Lung Health, Clinical Sciences Wing, University Hospitals of Leicester, Leicester, UK

Funded by an unrestricted grant from Schering-Plough, UK

Competing interest: Drs Bradding, Pavord and Brightling received an unrestricted grant from Schering-Plough to support this study. None of the other authors have a competing interest.

\section{REFERENCES}

1 Calverley PMA, Walker P. Chronic obstructive pulmonary disease. Lancet 2003;362:1053-61

2 Pauwels RA, Buist AS, Calverley PMA, et al. Global strategy for the diagnosis, management, and prevention of chronic obstructive pulmonary disease. NHLBI/WHO Global Initiative for Chronic Obstructive Lung Disease (GOLD) Workshop Summary. Am J Respir Crit Care Med 2001;163:1256-76.

3 National Institute for Clinical Excellence (NICE). Chronic obstractive pulmonary disease: national clinical guideline for management of chronic obstructive pulmonary disease in adults in primary and secondary care. Thorax 2004;59(Suppl I).

4 Pavord ID, Brightling CE, Woltmann G, et al. Non-eosinophilic corticosteroid unresponsive asthma. Lancet 1999;353:2213-4.

5 Keatings VM, Jatakanon A, Worsdell YM, et al. Effects of inhaled and oral glucocorticoids on inflammatory indices in asthma and COPD. Am J Respir Crit Care Med 1997; 155:542-8.

6 Keatings VM, Barnes PJ. Granulocyłe activation markers in induced sputum: comparison between chronic obstructive pulmonary disease, asthma, and normal subjects. Am J Respir Crit Care Med 1997;155:449-53.

7 Pizzichini E, Pizzichini MM, Gibson P, et al. Sputum eosinophilia predicts benefit from prednisone in smokers with chronic obstructive bronchitis. Am J Respir Crit Care Med 1998;158:1511-7. 
8 Brightling CE, Monteiro W, Ward R, et al. Sputum eosinophilia and short-term response to prednisolone in chronic obstructive pulmonary disease: a randomised controlled trial. Lancet 2000;356:1480-5.

9 Guyatt GH, Berman LB, Townsend M, et al. A measure of quality of life for clinical trials in chronic lung disease. Thorax 1987:42:773-8.

10 Brightling CE, Ward R, Goh KL, et al. Eosinophilic bronchitis is an important cause of chronic cough. Am J Respir Crit Care Med 1999;160:406-10.

11 Brightling CE, Ward R, Woltmann G, et al. Induced sputum inflammatory mediator concentrations in eosinophilic bronchitis and asthma. Am J Respir Crit Care Med 2000;162:878-82.

12 Tweeddale PM, Alexander F, McHardy GJ. Short term variability in FEV1 and bronchodilator responsiveness in patients with obstructive ventilatory defects. Thorax 1987;42:487-90.

13 Confalonieri M, Mainardi E, Della Porta R, et al. Inhaled corticosteroids reduce neutrophilic bronchial inflammation in patients with chronic obstructive pulmonary disease. Thorax 1998;53:583-5.

14 Gizycki MJ, Hattotuwa KL, Barnes N, et al. Effects of fluticasone propionate on inflammatory cells in COPD: an ultrastructural examination of endobronchial biopsy tissue. Thorax 2002;57:799-803.

15 Culpitt SV, Maziak W, Loukidis S, et al. Effect of high dose inhaled steroid on cells, cytokines, and proteases in induced sputum in chronic obstructive pulmonary disease. Am J Respir Crit Care Med 1999;160:1635-9.

16 Loppow D, Schleiss MB, Kanniess F, et al. In patients with chronic bronchitis a four week trial with inhaled steroids does not attenuate airway inflammation. Respir Med 2001; 95:115-21.

17 Yildiz F, Kaur AC, Ilgazali A, et al. Inhaled corticosteroids may reduce neutrophilic inflammation in patients with stable chronic obstructive pulmonary disease. Respiration 2000;67:71-6.

18 Louis RE, Cataldo D, Buckley MG, et al. Evidence of mast-cell activation in a subset of patients with eosinophilic chronic obstructive pulmonary disease. Eur Respir J 2002;20:325-31

19 Pauwels RA, Lofdahl CG, Laitinen LA, et al. Long-term treatment with inhaled budesonide in persons with mild chronic obstructive pulmonary disease who continue smoking. European Respiratory Society Study on Chronic Obstructive Pulmonary Disease. N Engl J Med 1999;340:1948-53.
20 Vestbo J, Sorensen T, Lange $\mathrm{P}$, et al. Long-term effect of inhaled budesonide in mild and moderate chronic obstructive pulmonary disease: a randomized controlled trial. Lancet 1999;353:1819-23.

21 Burge PS, Calverley PM, Jones PW, et al. Randomised, double blind, placebo controlled study of fluticasone propionate in patients with moderate to severe chronic obstructive pulmonary disease: the ISOLDE trial. BMJ 2000;320: 1297-303.

22 The Lung Health Study Research Group. Effect of inhaled triamcinolone on the decline in pulmonary function in chronic obstructive pulmonary disease: Lung Health Study II. N Engl J Med 2000;343:1902-9.

23 Fan VS, Bryson CL, Curtis JR, et al. Inhaled corticosteroids in chronic obstructive pulmonary disease and risk of death and hospitalisation: timedependent analysis. Am J Respir Crit Care Med 2003;168:1488-94.

24 Soriano JB, Vestbo J, Pride NB, et al. Survival in COPD patients after regular use fluticaone propionate and salmeterol in general practice. Eur Respir J 2002;20:819-25

25 Szafranski W, Cukier A, Ramirez A, et al. Efficacy and safety of budesonide/ formoterol in the management of chronic obstructive pulmonary disease. Eur Respir J 2003;21:74-81.

26 Jones PW, Willits LR, Burge PS, et al. Disease severity and the effect of fluticasone propionate on chronic obstructive pulmonary disease exacerbations. Eur Respir J 2003;21:68-73.

27 Mahler DA, Wire P, Horstman D, et al. Effectiveness of fluticasone propionate and salmeterol combination delivered via the Diskus device in the treatment of chronic obstructive pulmonary disease. Am J Respir Crit Care Med 2002; 166:1084-91.

28 Burge PS, Calverley PMA, Jones PW, et al. Prednisolone response in patients with chronic obstructive pulmonary disease: results from the ISOLDE study. Thorax 2003:58:654-8.

29 Pavord ID, Siva R, Brightling CE, et al. Prednisolone response in patients with COPD. Thorax 2004;59:179.

30 Green RH, Brightling CE, McKenna S, et al. Asthma exacerbations and sputum eosinophil counts: a randomised controlled trial. Lancet 2002;360:1715-21. 